\section{Disseminated Intravascular Coagulation in Meningococcal Infection}

Sir,

The description by Fox in the recent issue of the Archives (October 1971) of histological evidence of widespread intravascular coagulation in 13 patients dying of the Waterhouse-Friderichsen syndrome (with proved meningococcal septicaemia in two) and his suggestion that heparin should be used in such patients, prompts us to report the following patient:-

A male infant aged 4 months was admitted with the complaint of sudden onset of fever, drowsiness, and purpuric rash on his arms, legs, trunk, and face. He was born of an uneventful pregnancy by spontaneous vertex delivery with a birthweight of $4 \cdot 13 \mathrm{~kg}$. He was breast fed from birth and had had no illnesses.

On examination he was critically ill and had a temperature of $40^{\circ} \mathrm{C}$. Pulse rate was 120 beats a minute and regular. Blood pressure was $80 / 40 \mathrm{~mm} \mathrm{Hg}(5 \mathrm{~cm}$ cuff right arm, lying). He had widespread purpuric spots on his face, trunk, and extremities, and most of them were confluent. His peripheral circulation was good. Anterior fontanelle tension was normal and there was no nuchal rigidity. Examination of major systems was normal.

Blood urea and electrolytes were normal. Gramnegative diplococci, morphologically identical with meningococci, were found in a smear made from a purpuric spot. Blood and CSF cultures were sterile. The CSF was normal.

Treatment with penicillin, sulphadimidine, and hydrocortisone was initiated. Meningococci were subsequently isolated from a sib.

On the night of admission (day 0 ) the platelet count was $190,000 / \mathrm{mm}^{3}$, with numerous platelets present on

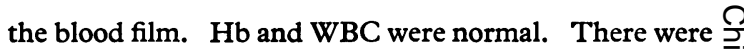
no burr cells.

The following morning (day 1 ) the platelet count had fallen to $35,000 / \mathrm{mm}^{3}$ and platelets were scanty on the $\vec{T}$ film. $\mathrm{Hb}$ was $11 \mathrm{~g} / 100 \mathrm{ml}$ and there was a leuco- 0 cytosis $\left(37,000 / \mathrm{mm}^{3}\right)$ with an increase in polymorphs, $\frac{\bar{\sigma}}{\sigma}$ lymphocytes, and Turk cells. Burr cells were still $\overline{\bar{c}}$ absent.

This rapid drop in platelet count coincided with a $\varrho$ progressive clinical deterioration, with extension of the purpura which became confluent and necrotic in areas, $\overrightarrow{0}$ and the occurrence of fits. Rapid coagulation screening tests showed a grossly prolonged Quick's prothrombin $\overrightarrow{\vec{\omega}}$ time of $40 \mathrm{sec}$ (control $11 \mathrm{sec}$ ) and a slight reduction of $\stackrel{\omega}{\sigma}$ the fibrinogen titre to $1: 64$ (control $1: 128$ ). The combination of these findings was thought to be strongly suggestive of disseminated intravascular coagulation and $\vec{V}$ we decided to start serial coagulation studies and treat- is ment with continuous heparin $(25 \mu / \mathrm{kg}$ per hr). The of sequential changes are shown in the Table. The $\omega$ heparin was stopped on day 6 when the platelet count was normal. (All drugs were given intravenously while on heparin to avoid IM injections.)

The low levels of the consumable coagulation factors $\left(V, V I I I\right.$, and fibrinogen) and plasminogen, with grossly $\frac{7}{2}$ raised fibrin degradation products (FDPs), together with a return to normal after heparin were conclusive $\overrightarrow{0}$ evidence of consumptive coagulopathy, this being the $N$ in vivo equivalent of the pathological demonstration of intravascular fibrin deposition reported by Fox. Burr cells appeared on day 2 followed by a fall in $\mathrm{Hb}$ level, presumably as a consequence of intravascular fibrin deposition.

The correction of this consumptive coagulopathy was followed by a return to normal of the platelet count; together with clinical improvement, no further fits and no further extension of purpura. The patient made an uneventful recovery with no residual neurological defect on subsequent follow-up.

TABLE

Meningococcal Septicaemia

\begin{tabular}{|c|c|c|c|c|c|c|}
\hline Day & Platelets & FDPs & Fibrinogen & $\underline{\overline{\mathbf{v}}}$ & AHG & Plasminogen \\
\hline \multirow[t]{2}{*}{1} & 35,000 & 160 & 227 & $2 \%$ & $23 \%$ & 0.44 \\
\hline & & & R Heparin & $25 \mu / \mathrm{kg}$ per hr & - & 一 \\
\hline 2 & 23,000 & 80 & 328 & $10 \%$ & $75 \%$ & 0.44 \\
\hline 4 & 71,000 & 80 & 421 & $90 \%$ & $150 \%$ & $1 \cdot 33$ \\
\hline 5 & 123,000 & 40 & 332 & $80 \%$ & $120 \%$ & $1 \cdot 11$ \\
\hline 6 & 163,000 & 40 & 318 & $110 \%$ & $105 \%$ & $1 \cdot 33$ \\
\hline $\begin{array}{c}\text { Normal } \\
\text { Values }\end{array}$ & $>150,000 / \mathrm{mm}^{3}$ & $>5 \mu / \mathrm{ml}$ & $>300 \mathrm{mg} / 100 \mathrm{ml}$ & $50-200 \%$ & $50-200 \%$ & $>3.0$ c.u. $/ \mathrm{ml}$ \\
\hline
\end{tabular}


The potential value of heparin therapy in this disorder has similarly been shown by Abildgaard et al. (1967); Hitzig et al. (1968); Winkelstein et al. (1969), and Ellman (1971), but is not widely appreciated in this country. This may constitute a serious omission in management since it is the patient with evidence of intravascular coagulation in whom there is a poor prognosis (McGehee, Rapaport, and Hjort, 1967; Evans et al., 1969).

We are glad to acknowledge the co-operation of Dr. R. A. Shanks who was in clinical charge of the patient during this study.

M. L. N. WILLOUGHBY, SHEILA MCMORRIS, and K. M. GOEL

Royal Hospital for Sick Children, Glasgow.
Abildgaard, C. F., Corrigan, J. J., Seeler, R. A., Simone, J. V., and Schulman, I. (1967). Meningococcemia associated with intravascular coagulation. Pediatrics, 40, 78.

Ellman, L. (1971). Meningococcemia and consumption coagulopathy treated with heparin and dextran 70. Archives of Internal Medicine, 127, 134.

Evans, R. W., Glick, B., Kimball, F. et al. (1969). Fatal intravascular consumption coagulopathy in meningococcal sepsis. American Fournal of Medicine, 46, 910.

Fox, B. (1971). Disseminated intravascular coagulation and the Waterhouse-Friderichsen Syndrome. Archives of Disease in Childhood, 46, 680.

McGehee, W. G., Rapaport, S. I., and Hjort, P. F. (1967). Intravascular coagulation in fulminant meningococcemia. Annals of Internal Medicine, 67, 250.

Hitzig, W. H., Straub, P. W., Lo, S. S., and Frick, P. G. (1968). Disseminated intravascular coagulation. Clinical experience with anticoagulant therapy in the management of disseminated intravascular coagulation in children. Proceedings of the Royal Society of Medicine, 61, 1138.

Winkelstein, A., Songster, C. L., Caras, T. S. et al. (1969). Fulminant meningococcemia and disseminated intravascular coagulation. Archives of Internal Medicine, 124, 55. 